\title{
6. EL PATRIMONIO NACIONAL
}

M. ${ }^{a}$ VICTORIA GARCIA-ATANCE Y GARCIAA DE MORA

Profesora Titular de Derecho Constitucional

UNED 


\section{SUMARIO}

I. ORIGEN.-II. JUSTIFICACION DE SU CONDICIÓN DE INSTITUCIÓN ADMINISTRATIVA.-III. EVOLUCIÓN POLITICA DEL PATRIMONIO NACIONAL A LO LARGO DEL CONSTITUCIONALISMO HISTORICO ESPAÑOL.-IV. SU REGULACIÓN CONSTITUCIONAL.-V. REGULACIÓN JURIDICA DEL PATRIMONIO NACIONAL.-CONCLUSIONES. 
Revista de Derecho Político, núm. 33, 1991, pp. 151-171

\title{
6. EL PATRIMONIO NACIONAL
}

\author{
POR

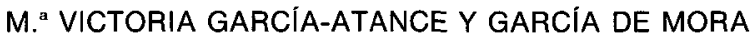 \\ Profesora Titular de Derecho Constitucional
}

UNED

\section{ORIGEN}

Quizá una visión superficial del estudio de esta institución junto con las demás instituciones administrativas af servicio de la Corona: Dotación de la Corona y la Casa del Rey, podria conducir a la conclusión de que son éstas unas instituciones poco relevantes y de escaso interés dentro del ámbito de la Corona; sin embargo, hay una serie de consideraciones que hacen rectificar esa primera impresión.

En primer lugar, estas instituciones no son exclusivas de la Monarquía, sino también de las Jefaturas de Estado de signo republicano con distinta nomenclatura y alcance, lo que, como apunta BASSOLS COMA ${ }^{\text {, }}$ aporta un trasfondo común en el Derecho Comparado, que, a nuestro modo de ver, le confiere un relieve singular.

En segundo lugar, son instituciones de amplia raigambre histórica, tanto en la etapa de monarquía patrimonial, como en la monarquía limitada, monarquía moderada y parlamentaria, y que si bien no sirven para caracterizar por sí mismas nuestro tipo de monarquía como forma de Estado, sí que ilustran el cambio cualitativo del ejercicio del tipo de Jefatura de Estado monárquico.

1 Bassols Coma, M.: «Instituciones administrativas al servicio de la Corona: Dotación de la Corona, Casa de Su Majestad el Rey, Patrimonio Nacional», en La Corona y la Monarquía Parlamentaria en la Constitución de 1978, Sección de Publicaciones de la Facultad de Derecho. Universidad Complutense, Madrid 1983, página 154. 
Por último, porque a través de sus sucesivas transformaciones han jugado un rol absolutamente clave en la formación del estado actual, como lo demuestra que lo que originariamente se reconocía como Patrimonio Real, diera su origen al Patrimonio del Estado (bienes demaniales y patrimoniales) y a la Hacienda Pública.

Aunque el Patrimonio es una institución común a las Jefaturas del Estado monárquica y republicana, como señalábamos con anterioridad, el origen de la institución es típicamente monárquica, siendo precisamente por obra del constitucionalismo como se produce la transformación de la Monarquía Patrimonial en la de Patrimonio de la Corona, como afirma RUIZ DEL CASTILLO ${ }^{2}$; en el primer caso, el reino era patrimonio del Rey, y en el segundo caso, el Rey poseía un patrimonio a título de institución, pero sobre el que ya no ejercía ningún «dominio eminente» sobre la propiedad de sus súbditos.

Avanzando un paso más, y en esa misma línea, el Profesor TORRES DEL MORAL ${ }^{3}$ afirma que la progresiva distinción entre el patrimonio regio y el patrimonio del Estado hay que conectarla con la transición de la Monarquía patrimonial hacia la Monarquía constitucional.

\section{JUSTIFICACIÓN DE SU CONDICIÓN DE INSTITUCIÓN ADMINISTRATIVA}

El Patrimonio Nacional se inserta en el ámbito de las Instituciones administrativas al servicio de la Corona, junto con la Dotación de la Corona y la Casa del Rey.

Aun a riesgo de la aparente impropiedad de tal calificación, como señala BASSOLS COMA ${ }^{4}$, del Patrimonio Nacional como institución administrativa, hay dos consideraciones que avalan esta calificación:

1. De una parte, como sostiene Bassols Coma, por la configuración de la Corona como un órgano constitucional - de naturaleza especial respecto a los demás órganos constitucionales-, pero que al igual que éstos,

2 Ruiz del Castillo, C.: Manual de Derecho Político, I, Madrid, Ed. Reus, 1939, pág. 660 .

3 Torres del Moral, A.: Principios de Derecho Constitucional español, volumen II, Madrid, Átomo, 2. ${ }^{\mathrm{a}}$ edic., 1988, pág. 23.

4 Bassols Coma, M.: “Instituciones administrativas al servicio de la Corona..."; op. cit., pág. 155. 
requiere una apoyatura administrativa autónoma, para el cumplimiento de sus funciones constitucionales, y que tiene cobertura en el artículo 65 de la CE.

En el mismo sentido, TORRES DEL MORAL ${ }^{5}$ reconoce en estas Instituciones una esfera de actividad al servicio de las funciones de la Corona, que al igual que los demás órganos constitucionales requiere una organización y regulación de ese núcleo administrativo puesto a su servicio.

2. La terminología de la Institución administrativa resulta además adecuada porque el concepto de Administración pública ha desbordado en la actualidad su encuadramiento en el ámbito del Poder Ejecutivo, como afirma Bassols Coma, presidiendo otras organizaciones públicas que no se insertan dentro de tal Poder Ejecutivo necesariamente, lo cual permite calificar a determinadas instituciones como «Administrativas», aun cuando no formen parte propiamente del Poder Ejecutivo.

En consecuencia, esta condición de institución administrativa ha de traducirse en una regulación administrativa del Patrimonio de la Corona.

\section{EVOLUCIÓN POLITICA DEL PATRIMONIO NACIONAL A LO LARGO DEL CONSTITUCIONALISMO HISTÓRICO ESPAÑOL}

Siendo el Patrimonio Nacional una institución eminentemente monárquica, sin perjuicio de que también pueda predicarse de las Jefaturas de Estado republicanas, su origen hay que situarlo como señalábamos anteriormente en la Monarquía Patrimonial, en la que, como señala DE MOLINARI ${ }^{6}$, el Rey se comportaba como un propietario que explotaba una empresa, vivía de las rentas de la misma, con una total confusión entre los rendimientos privados y públicos.

A finales del Estado absoluto se observa una clara diferenciación entre el Patrimonio de la Corona y el del Estado, pero, sin embargo, el soberano, al no tener control político alguno, invocando sus derechos y na 22.

5 Torres del Moral, A.: Principios de Derecho Constitucional...., op. cit., pági-

6 De Molinari, M. G.: «L'evolution politique et la révolution». París 1884, págs. 96 y ss., citado por BAssols COMA, M., en «Instituciones administrativas al servicio de la Corona...», op. cit., pág. 160. 
prerrogativas, alteraba constantemente con actos de disposición la ordenación existente.

Esta situación se hace especialmente patente en la etapa ominosa de Fernando VII el Deseado, cuando a pesar de recogerse en la Constitución doceañista la separación del Patrimonio Real y Patrimonio privado de la Corona, dispone en su testamento del Patrimonio Real con tal arbitrariedad que siembra una profunda confusión en esta temática, traduciéndose en un retroceso en la materia, debiendo esperar a la Ley de 1865 sobre el Patrimonio de la Corona para clarificar definitivamente la cuestión, retrasando así - como señala BASSOLS COMA ${ }^{7}$ - la práctica de esta institución administrativa al servicio de la Corona, que el texto constitucional ya había perfilado.

Sin perjuicio de estas regresiones al antiguo Régimen, la evolución que en esta materia presenta nuestro constitucionalismo histórico puede resumirse del modo que sigue:

- El Estatuto de Bayona de 1808 dedica el Título IV a la Dotación de la Corona y en la misma comprende como Patrimonio:

"Los palacios de Madrid, El Escorial, San Ildefonso, Aranjuez, el Pardo y todos los demás que hasta entonces habian pertenecido a la Corona, incluyendo los bosques, parques y cercados y propiedades dependientes de ella, de cualquier naturaleza».

- La Constitución de Cádiz de 1912, en su artículo 214, establecía: «Pertenecen al Rey todos los palacios Reales que han disfrutado sus predecesores, debiendo señalar las Cortes la designación de los terrenos que estimaran convenientes para el recreo de la persona del Rey».

A tal efecto, en 1814 las Cortes dictaron disposiciones precisas sobre el patrimonio del Rey y su administración; disposiciones éstas que quedarian huecas tras el restablecimiento del régimen absolutista, volviéndose a la situación de confusión anterior, propia de la Monarquia patrimonial.

- El Estatuto Real de 1834 no preveía ninguna disposición sobre tal institución, como tampoco la hubo en la Constitución de 1837, ni en la de 1845, hasta que en la Constitución non nata de 1856, en su artícu-

7 Bassols Coma, M.: «Instituciones administrativas al servicio de la Corona...», op. cit., pág. 160 . 
lo 53, apartado 8, se estableció que la Corona (no el Rey) necesitaba la autorización de una ley especial para enajenar todo o parte de los bienes del Patrimonio de la Corona, remitiendo su regulación a una ley infraconstitucional.

Con la Ley de 12 de mayo de 1865 se fija el conjunto de bienes que formarian en lo sucesivo el Patrimonio de la Corona, vendiéndose lo demás en favor del Estado, a fin de descargar a la Hacienda Pública de sus deudas. Del dinero de la venta se destinaría el 75 por 100 al Tesoro y el 25 por 100 a la Casa de S. M. el Rey.

Esta ley suscitó gran controversia al haber sido contestado por la opinión pública; efectivamente, a la sazón se produce una enorme polémica que saltó a la prensa, y que tiene en Castelar su máximo exponente, del que ilustra Carmen LLORCA ${ }^{8}$ en su obra Emilio Castelar:

“Narváez, por fortalecer el trono ya muy desprestigiado, convence a la Reina de que concediera 90 millones de su patrimonio a favor del Tesoro Nacional, a lo que Isabel II accede con la generosidad que le era habitual y con el absoluto desconocimiento del valor del dinero, que también le era habitual... Narváez trata de hacer propaganda de la donación regia, pero oportunamente sale al paso un duro artículo de Castelar en La Democracia el 21 de febrero de 1865, "¿De quién es el Patrimonio Real?", pretendiendo que lo que aún era proyecto de Ley de 12 de mayo de 1865, no llegara a publicarse. En este sentido se preguntaba a los lectores: "¿Ha dado la intendencia de palacio algo que realmente sea suyo? El Patrimonio Real es Patrimonio de la Nación... La Casa Real vuelve al país una propiedad que es del país, y que por los desórdenes de los tiempos y por la incuria de los gobiernos y de las Cortes, se hallaba en sus manos".

El 23 de febrero aparece asimismo en La Democracia otro artículo de Manuel Bañó titulado «Cuentos, Cuentos», en el que se insiste en la cuestión desamortizadora, y afirmando que Madrid era una capital completamente cercada por posesiones regias. «Dondequiera que os dirijáis, tropezaréis con las tapias de una posesión real.»

El 25 de febrero, Emilio Castelar hace hincapié en «El Rasgo» en idénticos términos, pero en esta ocasión interviene el Gobierno secuestrando el periódico, siendo posteriormente Castelar destituido de su Cátedra de Madrid. Todo ello culminaría a fin de cuentas con la aprobación de la Ley de 12 de mayo de 1865. Esta norma es sumamente clasificadora

s Llorca, C.: Emilio Castelar, Biblioteca Nueva, Madrid 1966, pág. 87. 
como afirma COS DE GAYÓN ${ }^{9}$ ante el absoluto caos en la regulación de bienes adscritos al Patrimonio de la Corona.

Por primera vez en nuestra historia se define el contenido y alcance enumerativo de estos bienes, y por primera vez se establece que el patrimonio de la Corona es indivisible, inalienable e imprescriptible, requiriéndose una ley para todo tipo de donaciones o enajenaciones.

Finalizada la Revolución de 1868 con la expulsión de la Reina, la Constitución de 1869 silencia la cuestión, limitándose a la fórmula usual en su artículo 76 de la Dotación al Rey al principio de cada reinado, y la Ley de 18 de diciembre de 1869, declaró extinguido el Patrimonio de la Corona: "Los bienes y derechos comprendidos bajo la anterior denominación y la de Real Casa, revierten en pleno dominio al Estado. Los bienes que se incorporan al Estado se declaran en estado de venta, a excepción de los que se destinan a uso y servicio del Rey; los que por su carácter histórico y artístico deban conservarse, y los que convenga conservar para el servicio del Estado».

Por tanto, esta Ley de 18 de diciembre de 1868 es especialmente progresista al mencionar por primera vez la titularidad del Estado sobre estos bienes y únicamente su afectación a uso y servicio del Rey pudiéndose vislumbrar en la misma una gran semejanza con el artículo 2 de nuestra actual Ley del Patrimonio Nacional 23/1982, de 16 de junio, como luego podremos ver.

Proclamada la República el 11 de febrero de 1873 la Ley de 24 de julio de 1873 determinaría la incautación por la Ley de 26 de junio de 1876, devolviendo en gran parte su vigencia a la Ley 12 de mayo de 1865, aunque la Constitución de los Notables guarde silencio al respecto, limitándose en su artículo $\mathbf{5 7}$ a la fórmula usual de que la dotación económica al Rey y su familia se fijará por las Cortes al principo de cada reinado.

Tras la proclamación de la República de 1931 se produce la incautación del Patrimonio Real por el Estado, publicándose la Ley de 22 de marzo de 1932 por la que desaparece el Patrimonio de la Corona configurándose asi el Patrimonio de la República, definiéndose como destino preferente de dicho Patrimonio: «Los fines de carácter sanitario, docente, social y turistico.» Por primera vez, como afirma GARCÍA FERNÁNDEZ ${ }^{10}$, se establece un Consejo de Administración del Patrimonio, autónomo, que depende del Ministerio de Hacienda.

9 Cos de Gayón, F.: Historia jurídica del Patrimonio Real, Madrid 1881, cita Bassols COMA, M., en «Instituciones administrativas...», op. cit., pág. 176.

10 Garcia Fernandez, J., en Ponencia presentada en el Cursillo de Doctorado impartido por el Departamento de Derecho Constitucional de la Facultad de Derecho de la UNED, en fecha 12 de noviembre de 1990. 
Hay que destacar dos características especialmente reseñables de la presente regulación:

La existencia de una masa de bienes con destino artístico o medio ambiental (separado del Patrimonio del Estado).

Su diferenciación del conjunto de bienes del Patrimonio del Estado, para facilitar su gestión de manera ajena a la administración del Patrimonio del Estado.

Por su parte, en el régimen franquista, la Ley de 7 de marzo de 1940, articula el Patrimonio Nacional como un todo unitario, jurídico indivisible, quedando destinado, en la parte que se precise, al uso y servicio del Jefe del Estado, y correspondiendo su propiedad al Estado. Esta ley sigue en parte la fórmula de 1932, al mantener inalterable la masa de bienes que conforman el Patrimonio Nacional y mantiene, asimismo, el Consejo de Administración. Pero se diferencia, asimismo, en dos aspectos especialmente relevantes: de una parte, porque destina una serie de bienes para el uso y servicio del Jefe del Estado, y en segundo lugar, porque en su regulación aparecen los Reales Patronatos que había suprimido la República.

El tejer y destejer de nuestra historia constitucional habría necesariamente que dejar su impronta también en una institución como la del Patrimonio regio que tan íntimamente vinculado ha ido con la evolución de la institución monárquica y de la Jefatura del Estado.

\section{SU REGULACIÓN CONSTITUCIONAL}

Aunque, como afirma LÓPEZ GUERRA ${ }^{11}$, el artículo 65 CE parecía concebir la dotación económica de la Corona como único medio para facilitar el ejercicio de las funciones del Jefe del Estado establecidas por el artículo 56, sin embargo, el Título VII, de Economía y Hacienda, añade otros medios que facilitan el mejor funcionamiento de la Jefatura del Estado en el artículo 132-3 CE.

1 López Guerra, L.: «Dotación de la Corona», en Comentarios a las leyes politicas. Comentarios a la Constitución. Madrid, Edersa, vol. V, 1983, pág. 361. 
Este precepto constitucionaliza el Patrimonio Nacional, dejando su regulación a una ley posterior: Ley 23/1982, de 16 de junio, y a su Reglamento para su desarrollo aprobado por Real Decreto 485/1987, de 18 de marzo.

La Constitución acepta acríticamente el concepto de Patrimonio Nacional de 1940, como afirma GARCÍA FERNÁNDEZ ${ }^{12}$, con la finalidad de desvincular la masa de bienes del Patrimonio Nacional fuera de la Corona, lo que a su vez conferiría a estos bienes una naturaleza convergente con el Patrimonio del Estado, pero con elementos diferentes, como tendremos ocasión de analizar posteriormente.

En este precepto 132.3 de la Constitución se plantea toda la problemática patrimonial del Estado, como señala BASSOLS COMA ${ }^{13}$, prescribiendo la regulación del Patrimonio del Estado y del Patrimonio Nacional -su administración, defensa y conservación- por ley.

Estos bienes derivan directamente del antiguo Patrimonio Real, y han sido considerados como constitutivos de una categoria especial por su afectación al servicio de la Corona: «Para el servicio y realce de la dignidad de la institución real», según cita GARCÍA OVIEDO ${ }^{14}$.

El iter legislativo del precepto constitucional del Patrimonio Nacional siguió diferentes fases ${ }^{15}$ :

a) Silencio inicial al no recibir tratamiento en el Congreso de los Diputados - tanto en el Anteproyecto de la Ponencia redactora como tampoco en el texto del Congreso-.

b) Una segunda etapa en que la Comisión del Senado introduce el tema. Seria el Grupo Parlamentario de UCD, a través de su portavoz Chueca Goitia, quien presentaría la enmienda n. $^{\circ} 719$ pretendiendo introducir esta institución englobada en el marco del Patrimonio Histórico-Artístico, considerando al Patrimonio Nacional como una parte del Patrimonio artístico, si bien con características propias y remitiendo además su regulación a una ley orgánica: «Formando parte del Patrimonio o bienes culturales del Estado español ... existe también el Patrimonio Nacional ... con caracteris-

12 García Fernandez, Javier, en Ponencia presentada en el Cursillo de Doctorado impartido por el Departamento de Derecho Constitucional de la Facultad de Derecho de la UNED, 12 de noviembre de 1990. Trabajo inédito.

13 Bassols ComA, M.: «Instituciones administrativas al servicio de la Corona...", op. cit., pág. 179.

14 Garcia Oviedo, cita de López Guerra, L., op. cit., pág. 361. pág. 3500 .

15 Constitución Española. Trabajos Parlamentarios. Cortes Generales III, 
ticas propias ... Este Patrimonio que los reyes de España han ido acumulando en sus fundaciones y residencias por todo el territorio Nacional».

La enmienda del Senado de UCD sería secundada por el Grupo Socialista, si bien excluyendo el matiz de que su regulación lo fuera por ley orgánica.

c) Una tercera fase en tan controvertido precepto fue que una vez dictaminado por el Senado y al pasar a la Comisión Mixta Congreso-Senado, el 17 de octubre de 1978, se pretendería volver al texto del Congreso según el cual se silenciaba el Patrimonio Nacional como materia constitucional, integrándose de forma implícita en el Patrimonio Histórico-Artístico. Pero como señalaria HERNÁNDEZ GIL ${ }^{16}$, la inclusión del Patrimonio Nacional en el ámbito del Patrimonio Artístico no era solución acertada ya que todos los bienes integrables en él no tendrían esta naturaleza artística.

Por fin la tendencia inicial sería rectificada, apareciendo el Patrimonio Nacional como materia constitucional con entidad propia, tal y como aparece en el actual artículo 132-3, redactado por la Comisión Mixta ${ }^{17}$.

En este sentido, señala BASSOLS COMA ${ }^{18}$ que la desvinculación del Patrimonio Nacional considerado como fenómeno hacendístico, del tratamiento fundamentalmente histórico-cultural propio del Patrimonio Histórico, como señala el profesor GARCIA FERNÁNDEZ ${ }^{19}$ en su artículo "Presupuestos jurídico-constitucionales del Patrimonio Histórico», habría de influir necesariamente en la redacción de la Ley de 1982.

V. REGULACIÓN JURIDICA DEL PATRIMONIO NACIONAL

A diferencia de lo que sucedía con anterioridad a la Constitución, nuestra Norma Fundamental encomienda a una ley especial la regulación

\footnotetext{
16 Hernández Gil, A.: El cambio político español y la Constitución. Madrid, Edit. Planeta, 1982, pág. 331.

${ }_{17}$ Constitución Española. Trabajos Parlamentarios. Cortes Generales, volumen III, pág. 4869.

18 BAssols Coma, M.: «Instituciones administrativas al servicio de la Corona..., op. cit., pág. 183 .

19 Garcla Fernández, J.: «Presupuestos jurídico-constitucionales», en Revista de Derecho Político, n. ${ }^{\circ}$ 27-28. Madrid, UNED, 1988, pág. 198.
} 
del Patrimonio Nacional, que supone una «separación administrativa y presupuestaria" entre el Patrimonio Nacional y la Casa del Rey, como afirma LÓPEZ GUERRA ${ }^{20}$ y a su vez DIEEZ-PICAZO ${ }^{21}$, ocupándose de su regulación la Ley 23/1982, de 16 de junio, así como su Reglamento aprobado por Real Decreto 485/1987, de 18 de marzo, modificado posteriormente por Real Decreto 694/1989, de 16 de junio, por el que se modificaria la estructura orgánica del Consejo de Administración del Patrimonio Nacional, y la Ley 21/ 1986, de 23 de diciembre, de Presupuestos Generales del Estado para 1987.

En este sentido, la Ley 23/1982, de 16 de junio, reguladora del Patrimonio Nacional configura una norma absolutamente innovadora ${ }^{22}$, ya que contempla un conjunto de bienes adscritos al órgano constitucional de la Corona, pero su administración está vinculada o dependiente de un Consejo de Administración, que en última instancia depende del Gobierno y en concreto el Ministerio de Relaciones con las Cortes es el que tutela el Patrimonio Nacional.

1. Concepto: El artículo 2 de la Ley 23/1982, de 16 de junio de 1982, publicado en el $B O E$ de 22 de junio del mismo año, establece: «Tienen la calificación jurídica de bienes del Patrimonio Nacional los de titularidad del Estado afectados al uso y servicio del Rey y de su Real Familia”.

Dos datos determinantes destacan de este articulo la distinción entre la titularidad y la afectación.

2. En cuanto a la titularidad, la ley refleja diáfanamente que los bienes del Patrimonio Nacional son de titularidad estatal, esto es, del Estado como institución, y no de la Nación o de la Corona, como afirma BASSOLS COMA ${ }^{23}$, quedando afectados al uso del Rey, no como persona individual sino como titular de la Jefatura del Estado, y no necesariamente como titular de la Corona, aunque la propia ley no quiera excluir frontalmente esta idea, como se observa en el artículo 8, apartado 2, letra $j$ : «Corresponde al Consejo de Administración... la propuesta al Gobierno de afectación de bienes muebles e inmuebles al uso y servicio de la Corona».

20 López Guerra, L.: «Dotación de la Corona», en Comentarios a las leyes políticas..., op. cit., pág. 366 . na 124.

21 Diez-Picazo, L. M.: El régimen jurídico de la Casa del Rey, op. cit., pági-

22 Garcia Fernandez, J., en Ponencia presentada en el Cursillo de Doctorado impartido por el Departamento de Derecho Constitucional de la Facultad de Derecho de la UNED, en fecha 12 de noviembre de 1990. Trabajo inédito.

23 BAssols COMA, M.: «Instituciones administrativas...», op. cit., pág. 188. 
En todo caso, el Patrimonio Nacional se configura, pues, como una especialización funcional del Patrimonio del Estado, según Bassols ${ }^{24}$, para que la Corona ejerza dignamente la más alta representación del Estado que le atribuye el artículo 56 de la $\mathrm{CE}$.

Así, según Diez-Picazo ${ }^{25}$, el Rey y su Casa pueden servirse, disfrutar materialmente del Patrimonio Nacional, pero no ejercen sobre el mismo ninguna titularidad, sino tan sólo su disfrute, y no pueden, en consecuencia, efectuar ningún acto de disposición o administración sobre el mismo.

3. El otro carácter del Patrimonio Nacional era el de la afectación. Ésta tiene unas notas especificas:

3.a) Esta afectación no tiene una sustantividad histórica intrínseca - como afirma BASSOLS ${ }^{26}$-, sino que deriva ex novo de la propia ley. Esto es, no tiene una carga condicionadora, sino la mera afectación que la ley posterior a la Constitución le ha atribuido libremente. De manera que los bienes que figuran actualmente en el Patrimonio Nacional no coinciden, ni tienen por qué coincidir, con los bienes delimitados con anterioridad a esta ley.

Pero al mismo tiempo, la ley tiene en cuenta los Derechos históricos de la Corona, en referencia a los Patronatos Reales -artículo 2 in fine-: «Además se integran en el citado Patrimonio los derechos y cargos de Patronato sobre las fundaciones y Reales Patronatos", y en el mismo sentido se manifiesta el artículo 5 .

En definitiva, que aunque la configuración del Patrimonio Nacional esté delimitada ex lege, hay que reconocer jurídicamente los titulos de la Corona, como afirma BASSOLS COMA ${ }^{27}$, e igualmente considera la ley al Rey como causa de la calificación de un bien del Patrimonio Nacional, como establece el artículo 4, apartado 8, de la L.P.N.: «Integran el Patrimonio Nacional las donaciones hechas al Estado a través del Rey».

Si bien, dichas donaciones, legados y herencias deberán ser aceptados por el Consejo de Administración, según establece el artículo 7 , pág. 124.

24 Bassols Coma, M.: «Instituciones administrativas...», op. cit., pág. 124.

${ }_{25}$ DízZ-PICAZO, L. M.: «El régimen jurídico de la Casa del Rey...», op. cit.,

BAssols ComA, M.: «Instituciones administrativas...», op. cit., pág. 188. Ibidem, pág. 189. 
L.P.N., entendiéndose que las herencias lo serán a beneficio de inventario, como prescribe el artículo 8, letra I, de la Ley.

3.b) Esta afectación no es inalterable o estática sino que pueden afectarse nuevos bienes, o desafectarse, por haber cumplido su misión. Este carácter no estático de la afectación se desprende del artículo 4, apartado 8, que dice: «Integran el Patrimonio Nacional... las donaciones hechas al Estado a través del Rey y los demás bienes y derechos que se afecten al servicio de la Corona», asi como el artículo 8, letra $j$ : "La propuesta al Gobierno de afectación de bienes muebles e inmuebles al uso y servicio de la Corona».

3.c) La ley contempla dos tipos de afectación: una, directa o principal, la afectación de los bienes al uso y servicio del Rey y su Real Familia, como define el artículo 2 L.P.N., y otra, afectación concurrente, de orden cultural, científico y docente, como define el artículo 3 de la L.P.N. siempre y cuando sea compatible con la afectación principal, como afirma DÍEZPICAZO ${ }^{28}$, y en el mismo sentido BASSOLS COMA ${ }^{29}$, lo cual a nuestro modo de ver ha de entenderse como que, caso de incompatibilidad de afectación principal y concurrente, se resolverá la cuestión con la tajante exclusión de la afectación concurrente.

3.d) En la línea de una Socialización de la Cultura emprendida por el Estado social, como señala TORRES DEL MORAL ${ }^{30}$, la ley hace alarde de una exquisita sensibilidad en torno no sólo a los valores socio-culturales respecto a los que proyecta, como hemos visto, una afectación concurrente o subsidiaria, sino también en relación con el conjunto histórico-artístico y valores ecológicos y ambientales, como pone de manifiesto en las numerosas referencias que refleja:

- Artículo 6, apartado 3, L.P.N.: «A los bienes del Patrimonio Nacional que tengan valor histórico-artístico les será también de aplicación la ley del Patrimonio Histórico-Artístico Nacional,» lo que convierte a la Ley de Patrimonio Histórico-Artístico 16/1985, de 25 de junio, de aplicación concurrente o supletoria; lo cual explica a su vez la heterogeneidad de ésta a

${ }_{28}$ Diez-PiCAzo, L. M.: El régimen jurídico de la Casa del Rey..., op. cit., página 124.

29 Bassols Coma, M.: «Instituciones administrativas al servicio de la Corona», op. cit., pág. 190.

3o TORRES del MoRal, A.: Principios de Derecho Constitucional Español, tomo I, 2. a edic., Átomo edit., Madrid 1988, pág. 349, op. cit. 
la que alude el profesor GARCÍA FERNÁNDEZ ${ }^{31}$-artículo 8, apartado 2, letras $a, f, g, k$ -

El interés suscitado en la ley por los bienes de valor histórico-artístico se hace especialmente patente en la taxativa prohibición que hace el artículo 8, apartado 2, letra $k$, de Delegación de bienes muebles e inmuebles de valor histórico-artístico.

- Artículo 3, in fine, en el que se atribuye al Consejo de Administración la protección del ambiente y la ecologia, con especial mención al monte de El Pardo.

- Artículo 8, apartado 2, letra a: «La conservación, defensa y mejora de los bienes y derechos del Patrimonio Nacional corresponde al Consejo de Administración».

Dentro de este ámbito de conservación, defensa y mejora, merece la pena mencionar la reciente moción presentada por el Grupo Popular del Senado, a través de su portavoz, senador Van-Halen Acedo, en el Diario de Sesiones del Senado, $n .{ }^{\circ} 8$, de la sesión plenaria de fecha 28 de febrero de 1990 , en la que se solicitaba del Gobierno que procediera a revisar y modificar la normativa legal en materia de control y seguridad del Patrimonio Nacional, a la que hace referencia el artículo 8, apartado 2, letra $f$, como consecuencia del robo de tres lienzos, en agosto de 1989, en la Sala del Palacio Real de Madrid, dos de Velázquez y uno de Carreño de Miranda.

De igual modo se denuncia en esta moción la desaparición del capitel gótico del Monasterio de las Huelgas, importante pieza cinchada en hierro del siglo XVII y del que hoy existe tan sólo una réplica.

En consecuencia, la moción del Grupo Popular por la que se solicitaba del Gobierno la revisión y modificación de las medidas en torno a seguridad y conservación de los bienes del Patrimonio Nacional seria constestada por Martínez Sospedra en el sentido de que las pérdidas y falta de seguridad de los bienes del Patrimonio Nacional son, en todo caso, ejemplo de la mala administración y tutela de los mismos, pero que en todo caso esto es un problema de gestión, pero no un problema de cambio de normativa. pág. 199.

31 Garcia Fernandez, J.: «Presupuestos jurídico-constitucionales», op. cit., 
Sometida la moción a votación de los 214 votos emitidos, sólo 81 lo fueron a favor, 122 en contra y 11 abstenciones.

\section{Naturaleza jurídica de los bienes del Patrimonio Nacional.}

Resulta difícil determinar la naturaleza jurídica de los bienes que integran el Patrimonio Nacional, ya que la propia Ley no se pronuncia de forma explícita al respecto, sino que hay que deducirla del conjunto del articulado.

Es en concreto el artículo 6.1 de la Ley del Patrimonio Nacional el que se refiere a que el régimen jurídico de estos bienes será el definido por la propia Ley y el Reglamento: Real Decreto 485/1987, de 18 de marzo, aplicándose con carácter supletorio la Ley del Patrimonio del Estado de 15 de abril de 1964, como asimismo establece el artículo 6.1, excluyéndose, en consecuencia, a estos bienes del régimen de propiedad de los particulares que establecía el artículo 342 del C.c.

Por su parte, a los bienes que tengan valor histórico-artístico les será también de aplicación la legislación sobre el Patrimonio Histórico-Artístico, Ley 13/1985, de 25 de junio de 1985, tal y como prescribe el mencionado artículo 6, apartado 3 .

De estas notas del articulado cabe extraer las siguientes consecuencias, como afirma BASSOLS COMA ${ }^{32}$ :

"Que los bienes del Patrimonio Nacional se configuran como bienes del Estado sometidos a un régimen singular, a los que se aplica supletoriamente la Ley de Patrimonio del Estado, y no quedando sujetos al régimen de propiedad de los particulares que establece el artículo 342 del C.C.».

Por último hay que mencionar las notas de inembargabilidad, imprescriptibilidad e inalienabilidad, como características propias de estos bienes, según determina el artículo 6, apartado 2, de la Ley del Patrimonio Nacional, gozando así de un régimen muy similar al de los bienes de dominio público del Estado, como afirma DÍEZ-PICAZO ${ }^{33}$, y disfrutando de las mismas exenciones tributarias. Pero se diferencian a la vez de estos bienes de dominio públicio del Estado en lo siguiente:

32 Bassols Coma, M.: «Instituciones administrativas...», op. cit., pág. 192. na 124.

Díz-PICAzo, L. M.: El régimen jurídico de la Casa del Rey, op. cit., pági- 
- Por el fin concreto a que están afectados.

- Por ser gestionados por un órgano ad hoc.

- Por la exigencia de inscripción registral, requisito éste que no es necesario, como señala PAREJO GÁMIR ${ }^{34}$, para los bienes de dominio público estatal, tal y como establece el artículo 5 del Reglamento hipotecario.

En consecuencia, su naturaleza jurídica puede resumirse: Bienes del Estado con un régimen singular a los que se aplica la propia Ley del Patrimonio Nacional y el Reglamento que la desarrolla, y con carácter supletorio la Ley de Patrimonio del Estado, y en su caso la Ley del Patrimonio Histórico-Artístico Nacional; y que por su condición de bienes imprescriptibles, inalienables e inembargables, se aproximan a los bienes de dominio público, pero se diferencian de éstos por el fin concreto al que quedan afectados, por su administración por un órgano ad hoc y por ser exigida inscripción registral.

\section{Administración del Patrimonio Nacional.}

El Consejo de Administración del Patrimonio Nacional está constituido por un presidente, un gerente y un número de vocales que no superará el de diez, todos ellos profesionales de reconocido prestigio... Y debiendo concurrir en dos de estos miembros la condición de miembro del Ayuntamiento en cuyo término municipal radiquen bienes inmuebles integrados en el Patrimonio Nacional o en alguna de las Fundaciones gobernadas por su Consejo de Administración. Estos miembros son nombrados - como establece el artículo 8, apartado 1, de la Ley 23/1982, de 16 de junio, y por su parte el Reglamento de esta ley, en su artículo 66, apartado 2 mediante Real Decreto previa deliberación del Consejo de Ministros, a propuesta y con el refrendo del Presidente del Gobierno, desapareciendo así toda prerrogativa regia en su nombramiento.

Aquí se hace especialmente patente la separación administrativa entre el Patrimonio Nacional y la Casa del Rey de que hace gala nuestra

34 PARejo GámiR, R.: Protección registral y dominio público, Edit. Revista de Derecho Financiero, 1975, pág. 23, cita BAssols ComA, M.: "Instituciones...», op. cit., pág. 193. 
Constitución, como afirma C. FERNÁNDEZ-MIRANDA ${ }^{35}$, toda vez que la Casa Real no administra estos bienes, recayendo, por el contrario, esta obligación en el Consejo de Administración, el cual libera a la Corona de esta responsabilidad, que, como señala GARCÍA FERNÁNDEZ ${ }^{36}$, se hace recaer en un organismo ad hoc, y de la que en último extremo será responsable el Gobierno. Responsabilidad ésta respecto a la que ya ha habido iniciativa parlamentaria, como se puso de manifiesto, según vimos con anterioridad, en la moción presentada por un grupo parlamentario en el Senado.

Este Consejo de Administración ejerce, como afirma BASSOL COMA ${ }^{37}$, unas funciones fiduciarias respecto a los bienes que integran el Patrimonio Nacional. Su administración no se encomienda, pues, al Ministerio de Hacienda (Dirección General del Patrimonio), sino a un órgano ad hoc, dependiente de la Presidencia del Gobierno y no ya de la Corona, consiguiéndose así una separación auténtica de la Corona en su doble vertiente administrativa: gracias a la gestión del Patrimonio Nacional por un Consejo de Administración autónoma, y presupuestaria, merced a la desvinculación de aquélla, al configurar una masa de bienes de titularidad estatal, quedando únicamente vinculados a la Corona por su característica de afectación al uso y servicio de aquélla; y siguiendo, a efectos económicos, un régimen ajeno a la dotación económica de la Corona, a la que alude la profesora FERNÁNDEZ-MIRANDA CAMPOAMOR ${ }^{38}$.

El nombramiento por parte del Gobierno de los miembros que conforman el Consejo de Administración plantea la cuestión sobre el control de tal órgano ad hoc.

En este sentido parece aceptable el reconocimiento de la existencia de un control doble sobre este órgano:

- De índole parlamentaria, al considerar la actividad desplegada por el Consejo de Administración como una extensión de la actividad del

35 Fernández-Miranda Campoamor, C.: «La dotación de la Corona y la Casa del Rey", en Ponencia presentada en el Cursillo de Doctorado impartido por el Departamento de Derecho Constitucional de la Facultad de Derecho de la UNED, en fecha 12 de noviembre de 1990.

36 Garcia Fernandez, J., en Ponencia presentada en el Cursillo de Doctorado impartido por el Departamento de Derecho Constitucional de la Facultad de Derecho de la UNED, 12 de noviembre de 1990.

${ }_{37}$ Bassols COMA, M.: «Instituciones administrativas...», op. cit., pág. 195.

38 Fernández-Miranda Campoamor, C.: “La dotación de la Corona y la Casa del Rey» en Ponencia presentada en el Cursillo de Doctorado impártido por el Departamento de Derecho Constitucional de la Facultad de Derecho de la UNED, en fecha 12 de noviembre 1990. 
Gobierno, toda vez que éste es el último responsable, y en consecuenciase justifica que el Parlamento pueda proyectar un control sobre la actividad del Consejo de Administración.

Ayuntamiento.

\section{CONCLUSIONES}

De las lecturas y estudios efectuados en la elaboración del presente trabajo, así como de mi propia aportación, me parece interesante extraer las siguientes conclusiones:

1. Los avances y retrocesos de nuestra historia constitucional en torno a la monarquia absoluta se reflejan, asimismo, en la regulación de la presente institución, pues al estar el Patrimonio Real intimamente vinculado a la Corona en nuestra historia constitucional, se comprende que, al igual que aquélla, haya experimentado asimismo avances y regresiones en su regulación.

2. Su condición de Institución administrativa se justifica por el ámbito de proyección del Poder Ejecutivo, alcanzando en su expansión, instituciones que reciben la calificación de administrativas, aun sin pertenecer al ejecutivo.

3. El reconocimiento del Estado como titular único de los bienes que configuran el Patrimonio Nacional —como sucedió por primera vez en la Ley 18 de diciembre de 1869 - convierte a esta institución aplicable a la Jefatura del Estado, sea cual sea el signo de ésta: monárquica o republicana.

4. Los bienes del Patrimonio Nacional se proyectan como bienes del Estado sometidos a un régimen singular, siéndoles aplicable el régimen jurídico que específicamente se determina por la propia Ley del Patrimonio Nacional 23/1982, de 16 de junio, en su artículo 6, y el Reglamento de la Ley, aprobado por el Real Decreto 485/1987, de 18 de marzo, y con carácter supletorio la Ley de Patrimonio del Estado y en su caso la del Patrimonio Histórico-Artístico Nacional; excluyéndose, en consecuencia, el régimen de 
propiedad de los particulares que establece el Código civil en su artículo 342 .

5. La desvinculación presupuestaria del Patrimonio Nacional en relación con otras instituciones como la dotación económica de la Corona, en la que se insertaba el Patrimonio Nacional en tiempos pasados, supone una garantía en la diferenciación y no confusión entre los bienes del patrimonio privado del Rey sobre todo en materia de donaciones, legados y herencias efectuadas voluntariamente del patrimonio privado de aquél al Patrimonio Nacional.

6. La autonomía administrativa del Patrimonio Nacional respecto a la Corona viene determinada por su Consejo de Administración, que actúa independientemente de la Corona, y que, por el sistema de designación del mismo, proyecta la responsabilidad de su actividad al propio Gobierno, debiendo ser, en consecuencia, controlado por el Parlamento.

7. Otra conclusión viene definida por el carácter innovador de la presente Ley, al regular la Institución del Patrimonio Nacional, y a diferencia de lo que sucedia con anterioridad a la Constitución, con una clara separación administrativa y presupuestaria entre el Patrimonio Nacional y la Casa del Rey, como acabamos de señalar en las dos conclusiones anteriores.

8. La condición de titularidad estatal que recae sobre los bienes que conforman el Patrimonio Nacional y su mera afectación al uso y servicio del Rey y su Real Familia, impiden a la Corona cualquier acto de enajenación que pudiera efectuar el Rey sobre aquéllos.

9. El conjunto de bienes que forman el Patrimonio Nacional no es necesariamente permanente y estable de continuo, ya que esta masa de bienes puede aumentar o disminuir, reconociéndose al propio Rey causa de calificación de un bien del Patrimonio Nacional.

10. La afectación de los bienes del Patrimonio Nacional no es unidimensional, sino que en la medida en que la afectación principal y la concurrente sean compatibles cabe asignar a estos bienes un destino de carácter cultural y científico. 
11. El valor histórico-artístico que poseen algunos bienes del Patrimonio Nacional posibilita la aplicación con carácter concurrente de la Ley del Patrimonio Histórico-Artístico.

12. La masa de bienes que conforma el Patrimonio Nacional goza de una naturaleza similar a la de bienes de dominio público, por ser inembargables, imprescriptibles e inalienables, disfrutando, asimismo, de las mismas exenciones tributarias, pero difieren de éstos por su afectación a un fin concreto, por ser gestionados por un ente ad hoc y por serles exigible su inscripción registral. 